\title{
Effect of thermochromic coatings on the indoor thermal behavior of a case study building
}

\author{
Claudia Fabiani ${ }^{1,2 *}$, and Anna Laura Pisello $^{1,2}$ \\ ${ }^{1}$ CIRIAF - Interuniversity Research Center, University of Perugia, Via G. Duranti 67, 06125 Perugia, Italy \\ ${ }^{2}$ Department of Engineering, University of Perugia, Via G. Duranti 97, 06125 Perugia, Italy
}

\begin{abstract}
Passive systems and solutions aimed at improving local thermal comfort conditions represent a cutting-edge research field in building applications. However, only a few investigations were performed by taking into account the local distribution and spatial variability of the airflow generated by the application of both traditional and innovative passive strategies. The present research work is aimed at bridging such gap by modelling the indoor thermal environment of a case study prototype building, i.e. test-room, situated in central Italy, by taking into account the indoor heat transfer phenomena. In particular, a CFD model of the building is elaborated and used to predict the indoor thermal effect of an adaptive thermochromic envelope, compared to more traditional solutions. The simulation results are post-processed in terms of (i) indoor temperature and (ii) indoor airflows. The main findings confirm a non-negligible and positive impact of the thermochromic building envelope on the local indoor thermal comfort conditions in both summer and winter conditions, due to its capability of selectively tailor the absorption of heat gains and a function of the local boundary conditions.
\end{abstract}

\section{Introduction}

In recent years, several research contributions have been focusing on the effect of specific UHI mitigation strategies on the magnitude of the local heat island in different cities worldwide [1]. In this view, the introduction of green and cool roofing applications was shown to produce significant benefits in terms of summer thermal comfort improvement in the built environment [2]. However, although numerous research contributions demonstrated the beneficial effect of vegetated roofs and walls in buildings, these applications also require extensive economic and practice efforts for their implementation. In this scenario, cool materials (CMs) are among the most examined solutions and they have proven to be particularly useful, cost-effective and easily adaptable to the built environment [3]. Among these materials, thermochromics allow to produce an adaptive layer capable of tailoring its passive cooling contribution in response to the modification in the local temperature profile [4]. They are particularly appreciated by the scientific community, since they could be used for significantly reducing the most common drawback of cool applications: the so-called winter penalty. Cool roofs, indeed, are known for their ability to reflect most of the incoming solar radiation, and re-emit a large part of the absorbed one in the long-wave range. In this way, they inevitably end-up reducing the positive solar gains through the building walls and roof in winter, consequently increasing the building energy use for heating purposes in this period [5]. Replacing purely cool solutions with thermochromic alternatives was shown to positively affect the seasonal performance of the coating. Fabiani et al. [6], for example, found a 5.8\% reduction in the amount of heat transferred per meter square of roof in winter, in view of a $1.2 \%$ increase in terms of summer cooling loads per meter square of roof compared to a more common cool application in an urban canopy configuration. Yet, further studies are needed to more clearly evaluate the energy and indoor thermal comfort effect of these materials.

In this context, computational fluid dynamics (CFD) tools could represent a valuable asset to supplement and further boost the in-lab material development of thermochromic applications. Indeed, these tools have largely been used to predict the effect of innovative building envelopes with advanced thermal-optical properties in terms of (i) airflow distribution, (ii) air quality, and (iii) temperature field [7,8]. More in detail, many research studies focus on the CFD evaluation of the impact of the roof inclination, roof covering materials, and the geometry of the environment on the internal flow (i.e. laminar or turbulent regimes) and

* Corresponding author: claudia.fabiani@unipg.it 
temperature distribution in enclosed spaces $[9,10]$. Moreover, a huge effort in the use of CFD tools to predict the flow and thermal field in enclosed cavities with different geometrical characteristics such as attic spaces is registered $[5,11]$, by considering $10^{9} \leq \mathrm{Ra} \leq 10^{11}$ when turbulence occurs.

Based on the above, in this work, (i) we exploit the possible use of thermochromic materials for improving indoor thermal comfort conditions of a case study building, benchmarking their performance to common solutions and (ii) we use CFD simulations to properly describe the indoor airflow and thermal environment of buildings. By using CFD we determined the indoor air temperature spatial distribution inside the cavity by investigating at which height the passive cooling effect of the thermochromic membrane is extinguished and how it affects the obtained air temperature distribution. To this aim, a preliminary continuous monitoring of the main indoor-outdoor microclimate parameters was carried out to support the validation and calibration of the numerical CFD model of the building. Therefore, three scenarios were simulated and compared: (i) more traditional building envelope (standard non-cool surfaces), (ii) cool building envelope (characterized by the application of the cool roofing membrane and cool façade painting on the envelope), and (iii) thermochromic envelope (consisting of a thermochromic roofing membrane and a thermochromic façade painting).

\section{Description of the case study}

The case study building is a $3.78 \times 3.78 \times 2.85 \mathrm{~m}^{3}$, fully instrumented test-room located in central Italy, and designed according to the recent construction techniques [12]. Fig. 1 reports the pictures of the case study building before (Figu.1a) and after (Fig.1b) the application of the cool membrane and of the highly reflective painting. The building is characterized by a global fenestration ratio of about 0.041 , while the opaque envelope is made of an innovative construction stratigraphy, compliant with the Italian regulations in terms of walls thermal stationary properties, and representative of a common residential building in Italy. The specific characteristics of the test-room envelope components are specified in Table 1. All the real thermal properties and characteristic of the building envelope components have been used as input data in a calibrated analytic box model that allowed us to obtain the local boundary condition for the traditional and the thermochromicbased configuration [13].

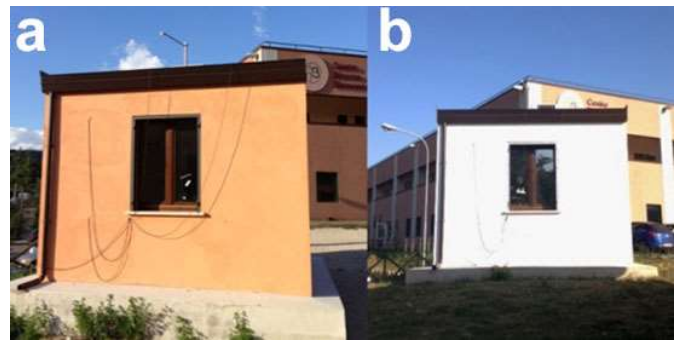

Fig. 1. (a) Cool and (b) standard configuration of the case study building.
Table 1. Building characteristics in terms of materials and main thermal properties of the envelope.

\begin{tabular}{|c|c|c|c|c|}
\hline & Material & $\begin{array}{c}\text { Thick. } \\
{[\mathrm{m}]}\end{array}$ & $\begin{array}{c}\text { Th. } \\
\text { Cond. } \\
{[\mathrm{W} / \mathrm{m} 2 \mathrm{~K}]}\end{array}$ & $\begin{array}{c}\text { Th. } \\
\text { Transm. } \\
{[\mathrm{W} / \mathrm{m} 2 \mathrm{~K}]}\end{array}$ \\
\hline \multirow{4}{*}{ Walls } & plaster & 0.02 & 0.50 & \multirow{4}{*}{0.49} \\
\hline & EPS & 0.09 & 0.04 & \\
\hline & brickwork & 0.30 & 0.27 & \\
\hline & plaster & 0.02 & 0.40 & \\
\hline \multirow{4}{*}{ Roof } & $\begin{array}{l}\text { waterproof } \\
\text { membrane }\end{array}$ & 0.01 & 0.23 & \multirow{4}{*}{0.25} \\
\hline & mineral wool & 0.10 & 0.04 & \\
\hline & concrete slab & 0.20 & 0.16 & \\
\hline & plaster & 0.015 & 0.40 & \\
\hline \multirow{3}{*}{ Floor } & cast concrete & 0.2 & 1.13 & \multirow{3}{*}{0.38} \\
\hline & stone wool & 0.08 & 0.04 & \\
\hline & linoleum & 0.015 & 0.17 & \\
\hline
\end{tabular}

\section{Methodology}

The methodology applied consists of the following main steps:

- continuous monitoring of the main indoor-outdoor microclimate parameters;

- CFD simulations in summer conditions;

- CFD simulations in winter conditions;

- post-processing and discussion of the achieved results.

In each weather condition, three building scenarios were assessed:

- Standard configuration (SC): building envelope covered by traditional non-cool materials ();

- Cool configuration (CC): building envelope covered by soiled high albedo materials i.e. cool roofing membrane and wall painting.

- Thermochromic configuration (TC): building envelope covered by innovative thermochromic materials i.e. roofing membrane and wall painting.

The traditional envelope materials are characterized by an albedo of 0.25 , the soiled cool envelope materials are characterized by a higher albedo, i.e. 0.50, while the thermochromic solutions have an albedo of 0.25 below $30^{\circ} \mathrm{C}$ and 0.50 above this limit. In each configuration, the building envelope materials present a thermal emissivity of 0.88 .

\subsection{Experimental monitoring campaign}

The continuous monitoring of the test-room building, equipped with a cool roof membrane and cool paintings on the walls, was carried out between September 2017 and September 2018. A complete weather station situated on the roof of a building in the proximity of the test-room was used to measure the main outdoor microclimate parameters Additionally, a dedicated microclimate monitoring station situated inside the testroom was used to collect the main indoor microclimate parameters for the validation of the model.

\subsection{Elaboration of the model}

In order to simulate the thermal performance and the airflow regime generated by the application of the three 
considered solutions, i.e. the traditional dark, advanced cool, and thermochromic envelope, within the test-room building, a three dimensional finite element CFD analysis was performed under transient conditions.

As can be seen in Fig.2, the simulation model was implemented considering a parallelepipedon with dimensions $2.95 \times 2.95 \times 2.55 \mathrm{~m}^{3}$, and consists of a single air domain discretized by means of 196832 domain elements, (11920 boundary elements, and 1128 edge elements) with a minimum size of $0.01 \mathrm{~m}$ and a maximum size of $0.1 \mathrm{~m}$. For this reason, the interaction between the building envelope and the ambient by means of radiative, convective and conductive phenomena was not explicitly considered. Nevertheless, for both winter and summer numerical models, these phenomena were indirectly implemented by means of temperature boundary conditions imposed on the different domain surfaces. These boundary conditions consisted of six user defined functions, produced by the previously described analytic box model, with a 10minutes time step. No slip conditions were imposed on each surface of the air domain.

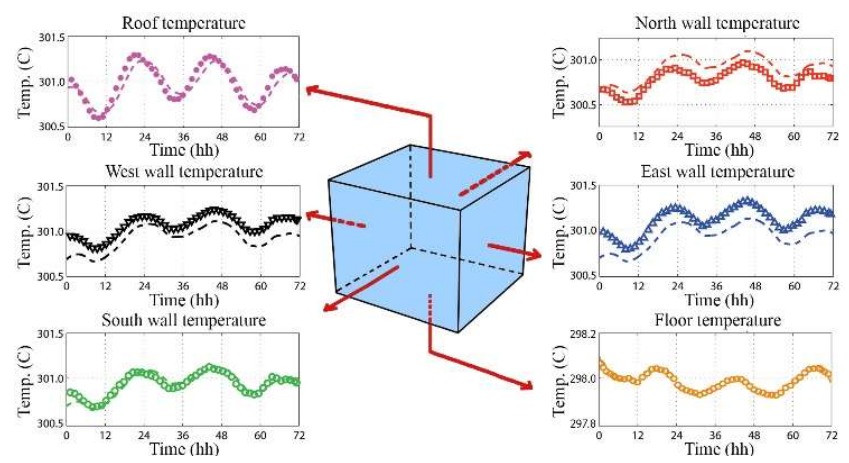

Fig. 2. Schematic of the simulated air domain, with the specific temperature boundary conditions.

\section{Results and discussions}

\subsection{Thermal effect in summer conditions}

In summer conditions, the case study represents a cuboid enclosure, heated from the above and the lateral surfaces. In this case, the change of density in the upper layer of the air domain, caused by the adduction between the air itself and the ceiling, determines a stagnation of the fluid, and inhibits the occurrence of a fully developed turbulent flow regime. Fig. 3 and Fig. 4 show the comparison between the temperature distribution generated in the different configurations (CC, TC, and $\mathrm{SC}$ ) inside the air domain in the hottest (12 PM) and the coldest (12 AM) hour of a typical summer day. As expected, each investigated building envelope denotes a notable thermal stratification inside the cavity height, with a huge heat conduction contribution, especially in the upper region, highlighting the necessity of investigating local cool and thermohcromic effect compared to traditional systems.

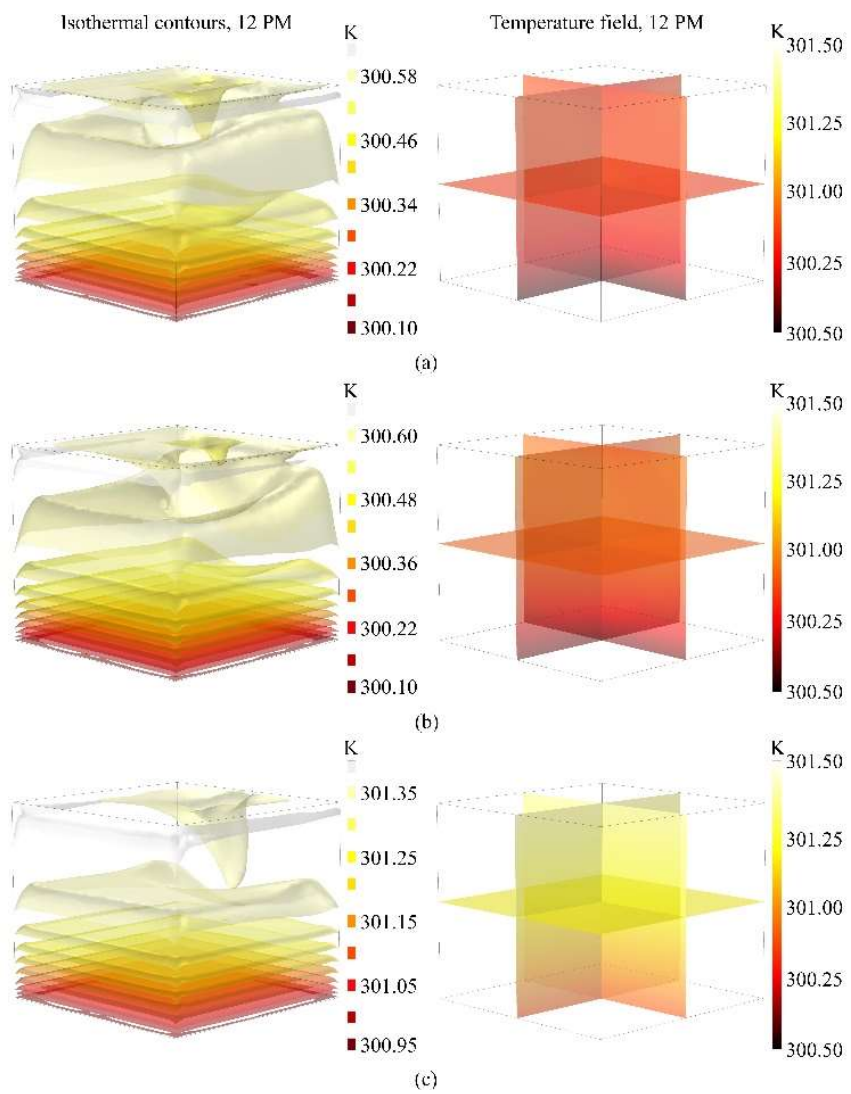

Fig. 3. Isothermal contours and temperature gradient for the (a) $\mathrm{CC}$, (b) the $\mathrm{TC}$, and (c) the $\mathrm{SC}$ at $12 \mathrm{PM}$ of August $4^{\text {th }}$ 2018.
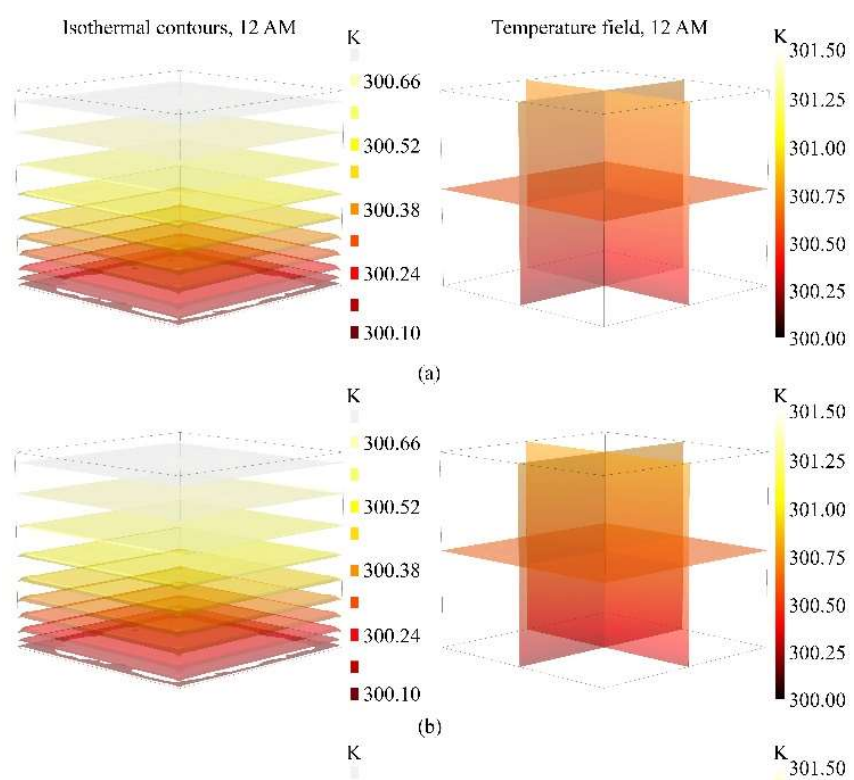

(a)

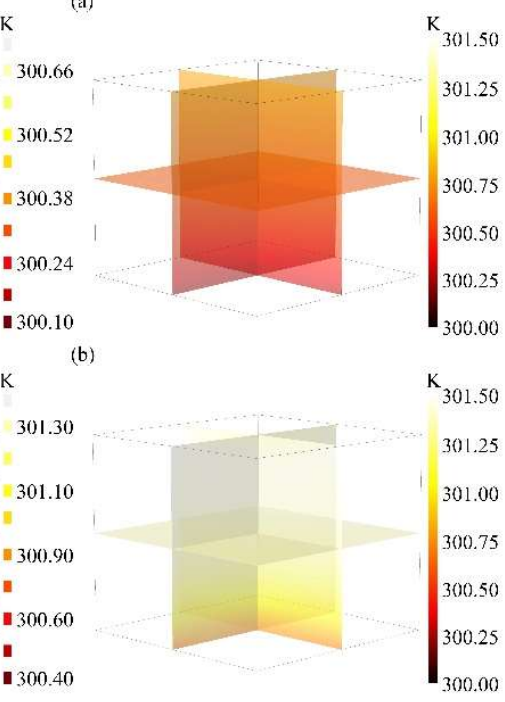

Fig. 4. Isothermal contours and temperature gradient for the (a) $\mathrm{CC}$, (b) the TC, and (c) the SC at $12 \mathrm{AM}$ of August $4^{\text {th }}$ 2018. 


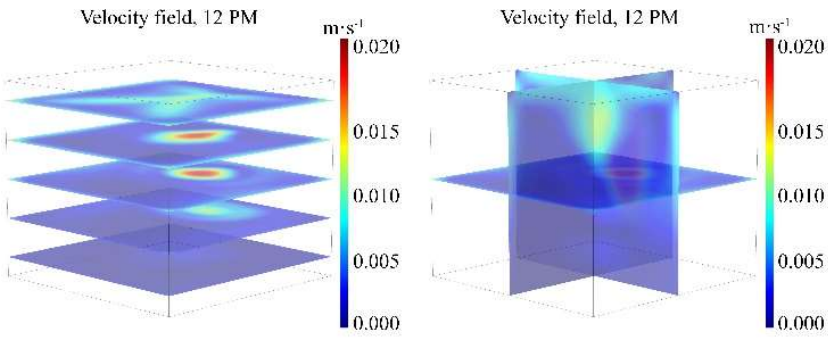

(a)

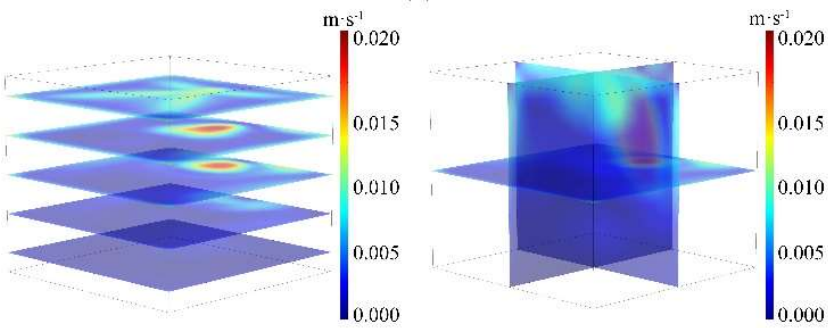

(b)
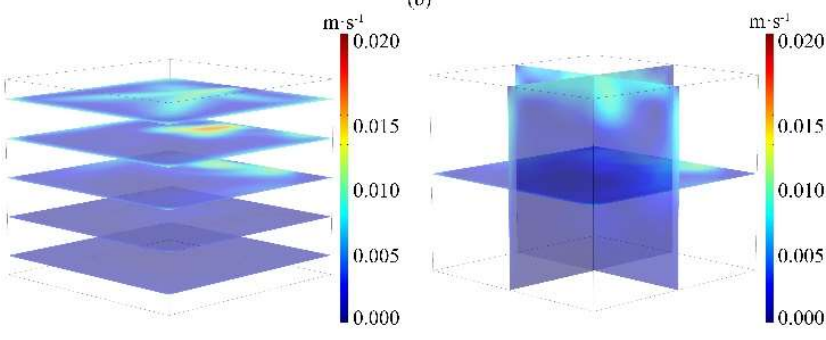

(c)

Fig.5. Velocity field for the (a) CC, (b) the TC, and (c) the SC at 12 PM of August $4^{\text {th }} 2018$.
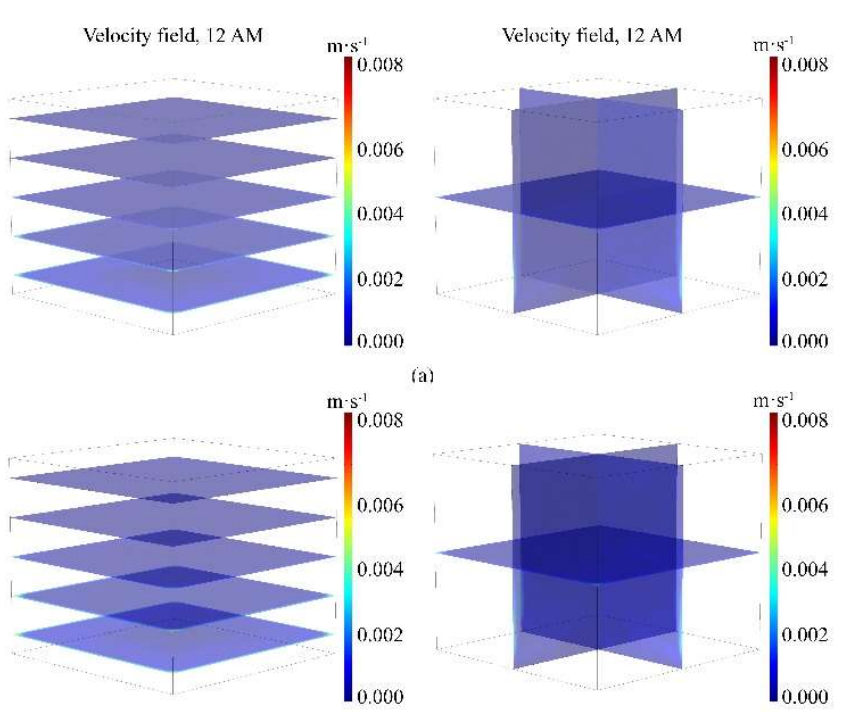

(b)
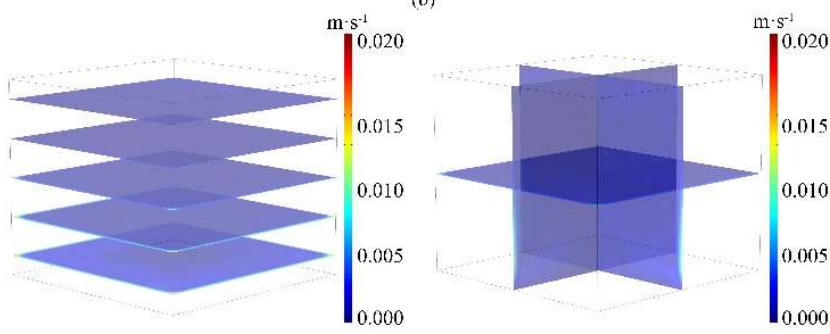

(c)

Fig.5. Velocity field for the (a) CC, (b) the TC, and (c) the $\mathrm{SC}$ at $12 \mathrm{AM}$ of August $4^{\text {th }} 2018$.
The dark envelope leads to hotter temperatures during the night, particularly above $1 \mathrm{~m}$ height, while the application of the cool and thermochromic solution allows to produce a more uniform and cooler environment, i.e. $-0.7^{\circ} \mathrm{C}$ at $1.8 \mathrm{~m}$ in the center of the room. This phenomenon could generate higher discomfort level for the occupants if compared to the high albedo scenarios. Additionally, the models, which are implemented considering 72 consecutive hours, allow appreciating a phenomenon which is not generally considered in the literature, where summer conditions are usually associated to heated walls from the above. In fact, during the day, the indoor surface of the roof is slightly colder than the air in the room, since the roof is responsible of huge rate of nightly thermal emission toward the sky compared to the indoor ceiling. This circumstance causes the air in direct contact with testroom ceiling to be cooled and move downward due to its higher density (see Fig.3 and Fig.5).

Nevertheless, Fig.5 and Fig. 6 show the velocity field generated inside the building by the three investigated roof configurations, and the development of descending plume at 12 PM can be noticed. During the night, on the other hand, the velocity field confirms the classic pseudo-diffusive stagnant core in the air domain, and the higher flow velocity along the walls, which validates the temperature stratification seen in Fig.5.

Concerning the effect of the thermochromic configuration on the local indoor environment, results from the temperature and the velocity field analyses demonstrate that the dynamic solution is capable of perfectly reproducing the performance of the soiled cool application, maintaining a relatively lower average temperature value within the simulated air cavity, and even lower punctual values above $1.5 \mathrm{~m}$ height. This close proximity between the two high-albedo envelopes is further corroborated by the comparison of the velocity field generated by the innovative cool and thermochromic envelope.

\subsection{Thermal effect in winter conditions}

In winter conditions, the indoor air temperature inside the test-room is lower in the cool scenario, as expected, while the thermochromic solution, due to its tailored optic performance, behaves just like the traditional case. Fig. 5 shows the temperature distribution inside the building for every configuration, i.e. (a) CC, (b) TC and (c) $\mathrm{SC}$, at $6 \mathrm{AM}$, i.e. coldest hour of the day.

The graphs show the capability of the dynamic solution to replicate the winter behavior of the traditional envelope and maintain a more uniform and warmer indoor environment, i.e. $+0.8^{\circ} \mathrm{C}$ and $+1.0^{\circ} \mathrm{C}$ on average in the early morning and the late afternoon, respectively.

In fact, when looking at Fig.6, the development of a classic convection system is wide evident in all the winter simulations. The fluid cells enable a larger convective heat transfer rate inside the cavity, which overtakes the conduction contribution in winter conditions in contrast to what happens in summer. 

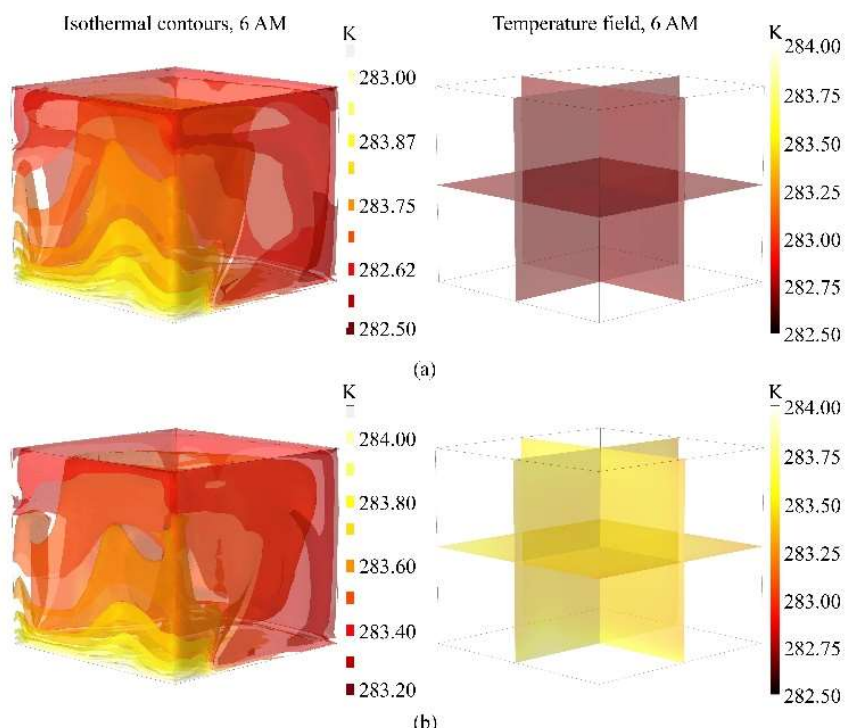

(b)

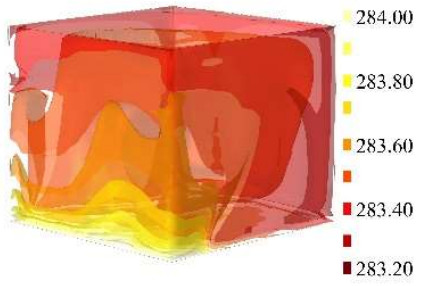

$\mathrm{K}_{284.00}$
283.75
283.50
283.25
283.00
282.75
282.50

(c)

Fig. 6. Isothermal contours and temperature gradient for the (a) $\mathrm{CC}$, (b) the TC, and (c) the SC at $6 \mathrm{AM}$ of December $22^{\text {nd }}$ 2018.
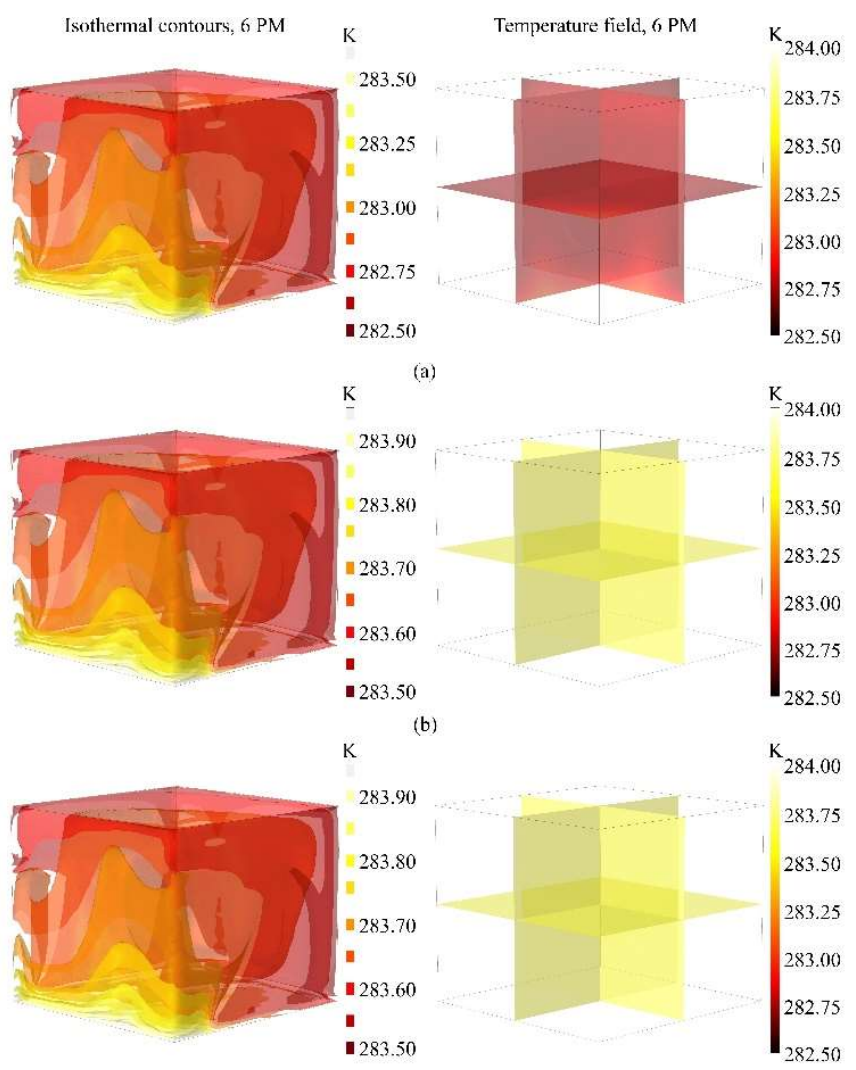

(c)

Fig. 6. Isothermal contours and temperature gradient for the (a) CC, (b) the TC, and (c) the SC at $6 \mathrm{PM}$ of December $22^{\text {nd }}$ 2018.
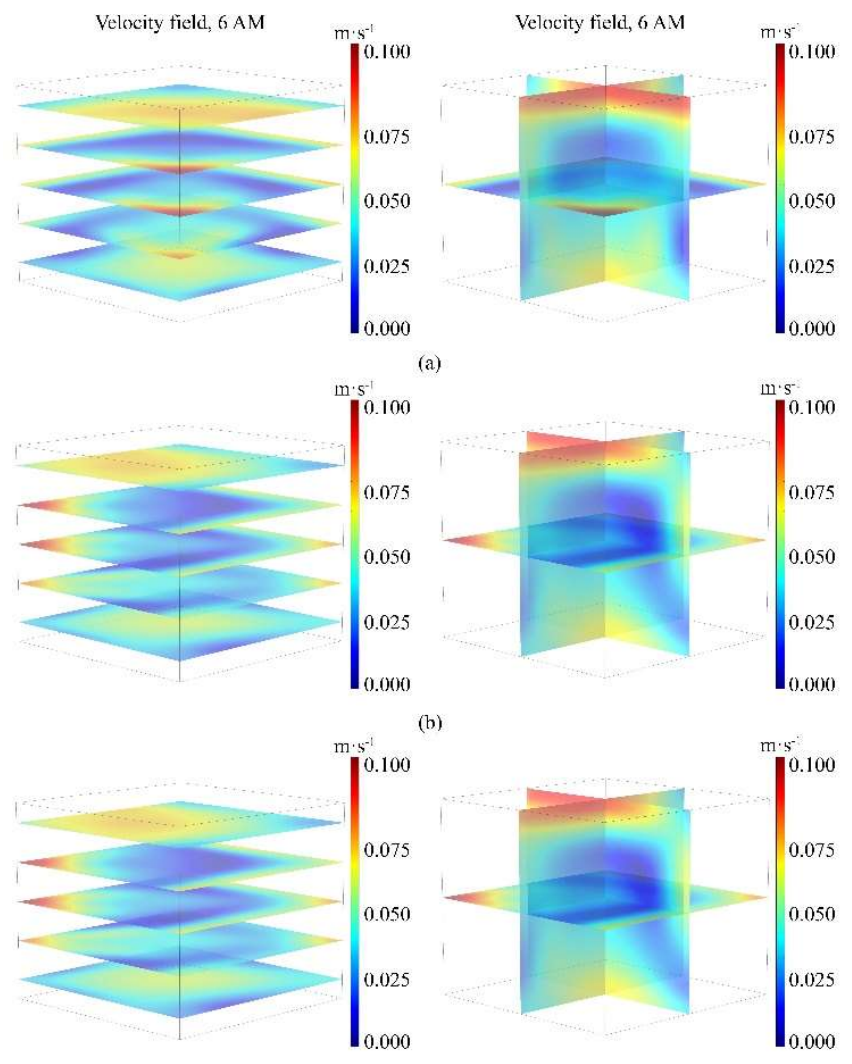

(c)

Fig.7. Velocity field for the (a) CC, (b) the TC, and (c) the $\mathrm{SC}$ at $6 \mathrm{AM}$ of December $22^{\text {nd }} 2018$.
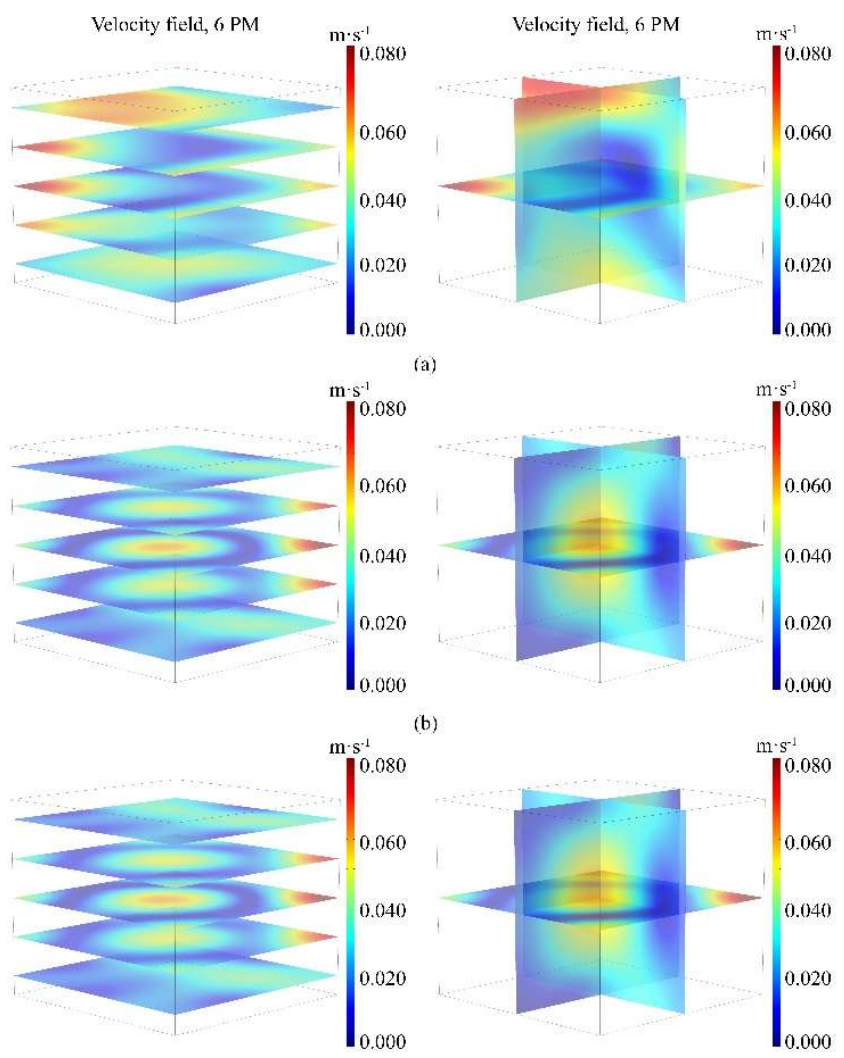

(c)

Fig.8. Velocity field for the (a) CC, (b) the TC, and (c) the $\mathrm{SC}$ at $6 \mathrm{PM}$ of December $22^{\text {nd }} 2018$. 


\section{Conclusions}

In this work, the potential effect of an innovative dynamic thermochromic application on the thermal performance of a prototype building is assessed and benchmarked against a traditional dark envelope configuration and a soiled cool envelope application.

More in detail, experimentally monitored data from a real case study building and the related outputs from a validated analytic box model of the same setup were used to simulate the effect of the dynamic material on the temperature and air flow distribution within the confined, free-floating environment of the test-room.

Results show that the application of the thermochromic membrane and wall painting allows to combine the positive summer passive cooling effect of the high albedo solution, with the desirable heat gain due to dark surfaces in winter. In particular, it was shown that the introduction of such dynamic materials allows to obtain non-negligible air-temperature reductions on the indoor environment (up to $0.7^{\circ} \mathrm{C}$ at $1.8 \mathrm{~m}$ height) in summer, while keeping a higher air temperature in winter, i.e. $+1.1^{\circ} \mathrm{C}$ at $1.8 \mathrm{~m}$ height.

The support from the European Union's Horizon 2020 program under grant agreement No 678407 (ZERO-PLUS) and the Italian Ministry of Education, University and Research (MIUR) through the funded Project of Relevant National Interest (PRIN) entitled 'SMART-BRICK: Novel strainsensing nano-composite clay brick enabling self-monitoring masonry structures' (protocol no. 2015MS5L27) is gratefully acknowledged.

\section{References}

1. C. O’Malley, P. Piroozfar, E.R.P. Farr, and F. Pomponi, Sustain. Cities Soc., 19, 222-235 (2015).

2. D. Li, E. Bou-Zeid, and M. Oppenheimer, Environ. Res. Lett., 9, (2014).

3. A.L. Pisello, V.L. Castaldo, C. Fabiani, and F. Cotana, Build. Environ., 97, 55-68 (2016).

4. X. Geng, W. Li, Y. Wang, J. Lu, J. Wang, N. Wang, J. Li, and X. Zhang, Appl. Energy, 217, 281-294 (2018).

5. M. Hosseini and H. Akbari, Adv. Build. Energy Res., 8, 1-13 (2014).

6. C. Fabiani, A.L. Pisello, E. Bou-Zeid, J. Yang, and F. Cotana, Appl. Energy, 247, 155-170 (2019).

7. Ali, Am. J. Eng. Appl. Sci., 7, 171-184 (2014).

8. J. Ni, B. Jin, B. Zhang, and X. Wang, Sustain., 9, 1-16 (2017).

9. S.C. Saha, J.C. Patterson, and C. Lei, Int. J. Therm. Sci., 49, 1899-1910 (2010).

10. T. Basak, S. Roy, S. Krishna Babu, and A.R. Balakrishnan, Int. J. Heat Mass Transf., 51, 4496-4505 (2008).

11. H. Asan and L. Namli, Energy Build., 33, 6973 (2000).
12. A.L. Pisello, F. Cotana, A. Nicolini, and C. Buratti, Energy Build., 80, 218-230 (2014).

13. C. Fabiani, V.L. Castaldo, and A.L. Pisello, Appl. Energy, 262, (2020). 